\title{
Resiliência: Uma Possibilidade de Adesão e Permanência na Prática do Futebol Feminino
}

Carlos Nazareno Ferreira Borges Simone Magalhães Lope Claudia Aleixo Alves Fábio Padilha Alves

Resumo: O presente trabalho investiga a possível existência de comportamento resiliente pelas meninas que praticam o futebol, tomando como amostra um grupo de meninas da classe pobre, praticantes da modalidade em Viçosa-MG. Diante das dificuldades encontradas para a adesão e permanência no futebol, comuns à classe soci-

al e ao gênero do grupo escolhido, acreditamos que a resiliência as mantém na prática, como recurso para a conquista de áreas de reserva masculina e participação no amplo movimento de emancipação social da mulher. A metodologia constou de observação partici pante, utilizando-se de anotações, fotografias e filmagens, que pudessem evidenciar o possível comportamento resiliente das meninas.

Palavras chave: Resiliência. Gênero. Futebol.

\section{Introdução}

O Projeto Gente é uma iniciativa extensionista promovida pelo Departamento de Educação Física da Universidade Federal de Viçosa/MG que desenvolve atividades educativas fundamentadas na corporeidade com jovens escolares da classe pobre, com perspectivas de inclusão e promoção social. Nos estudos de Silva et alii (2001), e Silva \& Pereira (2004), os quais estiveram levantando a história do Projeto (antes denominado de escolinha de futebol, porque iniciou somente com essa modalidade), podemos observar que esse surgiu da solicitação de associações de moradores dos Bairros do Laranjal e Bom Jesus, na cidade de Viçosa.

A partir dos estudos supramencionados, Borges et alii (2004) demonstram que entre os objetivos propostos pelo Projeto Gente, está o de favorecer estratégias de ação para uma educação alter-

Movimento, Porto Alegre, v.12, n. 01, p. 105-131, janeiro/abril de 2006. 
nativa de suporte à educação desenvolvida pelas estruturas educativas que cercam as crianças freqüentadoras das atividades. O futebol se constitui como atividade principal do Projeto, porém, pretende-se não a formação de talentos, mas um trabalho para a aprendizagem de um conteúdo corrente no cotidiano social que também favoreça a educação para um adequado uso do tempo livre, vindo a caracterizar uma tentativa de educação qualitativa do e para o lazer.

Apesar dos objetivos relevantes do Projeto, não encontramos referência dos motivos que levaram as associações a priorizar inicialmente a solicitação de atendimento a crianças apenas do gênero masculino, nem tampouco justificativas de porque os educadores do Projeto ofereceram as atividades também somente para os mesmos. Isso constituiu uma preocupação inicial na nossa investigação, pois entendemos que os motivos que geraram as preocupações das associações e dos educadores do Projeto atingem também às crianças do gênero feminino.

Atualmente, o Projeto conta com meninos e meninas na faixa etária de 12 a 17 anos, com nível de escolaridade compatível com a idade, uma vez que a frequiência regular à escola é condição para permanência no Projeto. São oferecidas aos dois gêneros as mesmas atividades, com a mesma filosofia de ação pedagógica, social e política. Essa foi a nossa segunda preocupação quando da construção do projeto de investigação, uma vez que podemos estar questionando sobre a possível necessidade de concepção única ou diferenciada que norteie as ações em função das diferenças de gênero.

No trabalho já citado de Borges et alii (2004), foi identificado que meninos e meninas aderem ao Projeto pelos mesmos motivos prioritários: $\mathrm{O}$ gosto pela modalidade futebol. Embora esse objetivo fosse comum, sentimos que havia alguma diferença para as meninas e isso passou a ser preocupação central para nós na investigação. $\mathrm{O}$ fato de não haver registros de evasão no grupo 
feminino desde que foi implementado, parecia reforçar que o motivo principal de adesão à modalidade era o gosto pela mesma. Porém, identificamos duas principais dificuldades para a permanência das meninas no projeto: a) a freqüente sujeição ao estereótipo da masculinização, b) a necessidade de auxiliar as mães em tarefas domésticas, uma vez que eram meninas de classe pobre, e as atividades eram nas manhãs de finais de semana.

Diante dessas dificuldades, pensamos que talvez o gosto não fosse suficiente para garantir a frequiência das meninas, então, passamos a supor a presença de um comportamento resiliente.

A resiliência é um conceito relativamente recente nas ciências sociais e tem sido abordado a partir de uma interface entre a Psicologia e a Sociologia. O conceito está relacionado à idéia de resistir, de superar situações difíceis, passando por elas e de alguma forma crescer pessoalmente e socialmente. A possível relação desse conceito de resiliência com a prática do futebol pelas meninas será tratada com maior atenção na continuidade desse texto.

Tem sido bastante recorrente na literatura de Sociologia do Esporte, sobretudo nos estudos sociológicos da mulher no esporte ${ }^{1}$, a afirmativa de que o esporte é uma área de reserva masculina, assim como muitas áreas de atuação dos indivíduos na sociedade. Por isso mesmo a mulher enfrentou, e ainda continua enfrentando, bastantes obstáculos quanto a sua participação nesse campo, sobretudo obstáculos que se traduzem em atitudes preconceituosas de segregação, ridicularização e estigmatização. Mas, elas resistiram e continuam resistindo, a ponto de conseguirem conquistar espaços cada vez maiores no campo esportivo. Sabemos que se a situação se apresenta assim no esporte como um todo, no futebol há agravantes, sobretudo no Brasil, onde a tradição estabelece a prática dessa modalidade - por motivos históricos, biológicos, psicológicos, entre outras asserções - como preponderantemente

1 Pfister(1997), Dunning (1994), Costa \& Guthrie (1994), Almeida (2003)

Movimento, Porto Alegre, v.12, n. 01, p. 105-131, janeiro/abril de 2006. 
adequada ao homem. Nesse caso, ao olharmos as meninas do Projeto Gente, e sabendo de suas adesões declaradamente atribuídas ao gosto pelo futebol, levantamos a seguinte questão: será que a participação espontânea no futebol estaria expressando, ainda que inconscientemente, um processo de resiliência diante da reserva masculina nessa modalidade esportiva?

Na implementação do estudo junto ao grupo de meninas, inferimos uma afirmação provisória positiva quanto a existência de comportamentos resilientes e, desse modo, pretendemos identificar a ratificação dessa suposição ou mesmo encontrar outros elementos teóricos que nos ajudem na compreensão da experiência vivida por esse grupo no Projeto Gente.

Cremos que as sendas de nosso trabalho perpassam por um estudo mais detalhado sobre o referencial da resiliência enquanto construto teórico, recorrendo com freqüência a diversos estudos, como os de Tavares (2001). Cremos também na necessidade de um levantamento dos estudos produzidos sobre a participação feminina em diversas áreas de reserva masculina, inclusive o esporte, por isso trazemos referências comparativas, como os estudos de Perim (2005) e Souza Neto et alii (2005). A fim de verificar o comportamento resiliente nas meninas do Projeto Gente, desenvolvemos um itinerário metodológico pelo qual os dados foram coletados na observação participante e através da aplicação de entrevistas a uma amostra constituída de cinco meninas do grupo praticante.

\section{Resiliência: Um Processo de Formação do Ser Humano}

Diversos estudos sobre resiliência tratam essa abordagem teórica a partir de conceitos extraídos da Física, e nesta área, considera-se resiliência como a capacidade de um material absorver energia sem sofrer deformação plástica ou permanente (Silva Jr. apud Yunes e Szymanski, 2001). No sentido psicossocial relaciona-se ao fato de pessoas, grupos ou comunidades, resistirem às situações difíceis, às adversidades e ainda aproveitar para crescer 
pessoalmente e socialmente. Metaforicamente, Yunes e Szymanski (2001) colocam que a relação tensão/pressão com deformaçãonão-permanente corresponderia à situação de risco/estresse/experiências adversas com respostas finais de adaptação/ajustamento no indivíduo. Uma expressão popular que estaríamos utilizando para entender a idéia de resiliência seria: "(enfrentar) levantar, sacudir a poeira e dar a volta por cima".

$\mathrm{Na}$ Psicologia, o conceito de resiliência no sentido de invulnerabilidade é o que norteia os estudos e produções científicas, contudo, diz-se de resiliente aquele que resiste, supera adversidades, sem afirmar que o indivíduo irá sair ileso da crise como implica o termo invulnerabilidade. Nessa área, a resiliência é utilizada para entender como crianças que vivem situações adversas no seu desenvolvimento - psíquico - sobrevivem com saúde emocional e alta competência.

O comportamento resiliente pode ser expresso em várias etapas da vida, na fase inicial do desenvolvimento ou ainda quando a pessoa já se encontra na fase adulta. Estudos como os de Alvarez (S/D) comprovam que algumas pessoas mudaram de hábitos gradativamente, deixando os vícios e passando a valorizar o trabalho, estabelecendo novos vínculos afetivos e até novas preocupações, após terem sido submetidas a situações consideradas difíceis.

Pesquisas, que acompanharam o desenvolvimento de algumas crianças e adolescentes até a fase adulta, citadas no artigo de Yunes e Szymanski (2001), indicam que existem fatores que caracterizam um grupo como resiliente, são eles: melhor desenvolvimento intelectual; maior nível de auto-estima; maior grau de autocontrole; famílias menos numerosas; menor incidência de conflitos nas famílias. Na mesma pesquisa foi constatado que os indivíduos considerados de alto risco tornaram-se adultos competentes, e mostra também, citando os estudos de Rutter, que os meninos são mais vulneráveis a agentes estressores físicos e psicossociais do que as meninas.

Movimento, Porto Alegre, v.12, n. 01, p. 105-131, janeiro/abril de 2006. 
Tavares (2001) afirma que é necessário pensar em sistemas e processos educativos que estabeleçam como meta a formação de pessoas mais resilientes capazes de enfrentar dificuldades na vida em sociedade visto que atualmente os indivíduos já procuram meios de "defender-se" fisicamente da violência estabelecida no cotidiano das grandes cidades - e por que não dizer, das pequenas também - seja por sistemas de vigilância ou até mesmo criando verdadeiras fortalezas em seus lares. Se fosse possível "desenvolver" nessas pessoas, que vivem com medo, um comportamento resiliente - de acordo com Ruegg apud Tavares (2001), resistente e perseverante face às dificuldades que encontra - estas teriam ao seu dispor não somente defesas físicas, mas também psicológicas e culturais. Além disso, os sistemas de educação e formação do cidadão devem possibilitar "o desenvolvimento de mecanismos físicos, biológicos, psíquicos, sociais, éticos, religiosos que o tornem mais resiliente, menos vulnerável e lhe permitam ser um agente, um ator ou, melhor dizendo, o autor eficaz na transformação e otimização da sociedade em que vive" (p. 48).

Durante o processo de formação do indivíduo é necessário que este seja instigado a pensar, a refletir, questionar e questionar-se. No entanto, os modelos de educação atuais ainda não têm conseguido o desenvolvimento dessas capacidades. O mais comum é vermos sistemas educacionais em que as pessoas respondem a perguntas previamente formuladas - na maioria das vezes não por aquele que é o responsável por fazê-las em tal momento - onde as respostas são as mesmas em qualquer parte do mundo e independente da pessoa que a emite. Em oposição a esse quadro, alunos e professores devem ser capazes de se deslumbrar e de questionar, constantemente, o mundo em que vivem e as situações às quais são submetidos. Os protagonistas do processo de ensino-aprendizagem devem interagir de forma a propor questões inovadoras com respostas construídas de maneira conjunta e não apenas responder às perguntas que outros levantaram (evidentemente

Movimento, Porto Alegre, v.12, n. 01, p. 105-131, janeiro/abril de 2006. 
com seus motivos) sem questioná-las e/ou adaptá-las à realidade em que vivem.

De acordo com o autor supracitado, se uma pessoa passar por esse tipo de educação tornar-se-á resiliente e será, então, flexível, criativa, aberta, livre, inteligente, emocionalmente equilibrada, autêntica, empática, disponível, comunicativa, capaz de resistir às mais diferentes situações parcialmente complicadas e difíceis, sem perder o equilíbrio, por mais adversas que se apresentem essas situações. Resiliência é, pois, um processo que vai se desenvolvendo durante a vida e é adquirida através da educação e também através das experiências e das dificuldades vividas e ultrapassadas (Glantz \& Johnson e Constantine et al. apud Pereira, 2001).

É possível também que sejam grandes líderes aqueles considerados resilientes, conforme podemos observar no estudo de Pereira (2001), quando a autora cita que grandes lideres políticos precisaram transpor adversidades na vida e mesmo após terem passado por tempos difíceis foram capazes de superá-las, tornando-se ainda pessoas de sucesso e formadores de opinião.

Com efeito, os resilientes têm sido indivíduos que possuem uma história de vida mais difícil e sinuosa - seja com a família, com outros que os cercam ou ainda com a carreira profissional que optam por seguir - e, mesmo assim atingem maior sabedoria e re-significam o sentido de sua existência e seu valor pessoal (Antunes, 2003).

O que dizer, então, da história das mulheres? Mesmo em face à supremacia masculina, em diversas áreas ditas "de reserva" desse gênero, elas vêm aspirando a ocupação de cargos e espaços antes somente alocados aos homens e, para "delírio" de alguns mais conservadores, hoje elas não só estão conseguindo ocupar grandes cargos em repartições públicas e privadas, como também adentram nos esportes que até bem pouco tempo atrás apenas eram praticados pelos homens.

Movimento, Porto Alegre, v.12, n. 01, p. 105-131, janeiro/abril de 2006 
Relação: mulher x conquistas diárias de áreas de reserva masculina

Na vasta literatura que aborda a história dos movimentos de luta das mulheres em busca da dignidade e do reconhecimento social em situação de igualdade em relação aos homens, encontramos freqüentemente alusão às conquistas que foram sendo alcançadas em diversas culturas, não sem pouco sofrimento, resistências e martírios. Mas, o resultado pode ser visto claramente hoje nas diversas ocupações de posições que as mulheres mantêm em uma sociedade que ainda está orientada por valores preponderantemente masculinos. Basta ver, a título de exemplo, o importante cargo ocupado hoje na Casa Civil da presidência da república do Brasil, pela Ministra Dilma Russef.

A luta da mulher pela conquista de áreas de reserva masculina, área de domínio masculino, também aconteceu no esporte e as mesmas dificuldades que as mulheres encontraram para se libertar dos papéis que lhes foram definidos socialmente ao longo do tempo, encontraram também no acesso à prática esportiva, isso porque o esporte desde sua criação tem sido também uma área de reserva masculina. Desde a antiguidade as mulheres estiveram excluídas do esporte e mesmo após a inclusão das mulheres nos Jogos Olímpicos modernos, elas ainda foram proibidas de participar de algumas competições. No futebol, por exemplo, as mulheres só iniciaram a sua participação em 1979.

Hoje observamos certo avanço na inclusão feminina no esporte, fato esse exemplificado pelos números dos Jogos Olímpicos de Sidney $^{2}$ em 2000, quando dos 10.651 atletas, 4069 eram mulheres e nos Jogos de 2004 esse número foi ainda maior, porém, algumas modalidades esportivas, entre as quais o futebol e as lutas, ainda mantiveram resistências à participação feminina, e apresentaram um

${ }^{2}$ Dados disponíveis em www.cob.org.br

Movimento, Porto Alegre, v.12, n. 01, p. 105-131, janeiro/abril de 2006. 
quantitativo maior de participação para o gênero masculino.

A história da mulher no esporte manifesta questões sociais e culturais dentro do contexto de cada lugar e de cada época, quando interesses religiosos, econômicos, políticos e sociais objetivaram mostrar a figura da mulher como frágil perante a força e vigor masculino, inclusive, pelas diferenças biológicas entre os dois sexos, isto é, parecia ser um consenso que em todas as dimensões o homem era considerado mais "forte" que a mulher. Os diferentes papéis atribuídos aos gêneros durante o século XIX até o início do século $\mathrm{XX}$, também no que diz respeito à prática e recomendações de atividades físicas, mostram bem a concepção androcêntrica que dominava o período. Assim, sabemos que tanto as atividades físicas recomendadas para os homens quanto as recomendadas para as mulheres, estavam permeadas de uma concepção higienista, com preocupação centrada na saúde. Contudo, ao homem estavam atrelados valores como a virilidade, a resistência para o trabalho, o maior adestramento para o combate. Para as mulheres, no entanto, as indicações de atividades físicas centralizavam-se na maior e melhor preparação para as funções de mãe e esposa, funções essas que demandavam a exigência de boa saúde e condição física, mesmo porque as mulheres eram consideradas frágeis e de condição física muito aquém dos seus companheiros homens.

Os aspectos mencionados que recomendavam as atividades físicas de forma diferenciada para homens e mulheres, aproximavam bastante os primeiros das características presentes na maioria dos esportes, enquanto para elas, tais atividades não mantinham relação com sua condição natural, ficando recomendadas com algumas restrições a prática do das seguintes atividades: tênis, ginástica, natação e o ciclismo. Essa última atividade - o ciclismo foi tolerada apenas com o uso de bicicletas que fossem ajustadas aos padrões dos vestidos da época. Todas essas modalidades não eram praticadas com fins competitivos, porém, algumas modificações na esfera social e no cenário político de várias nações implicaram em mudanças na esfera esportiva, assim como mudanças na

Movimento, Porto Alegre, v.12, n. 01, p. 105-131, janeiro/abril de 2006 
esfera esportiva também causaram mudanças sociais e políticas nas nações. Foi dessa forma, que em 1928, nos Jogos olímpicos de Estocolmo, as mulheres foram incluídas nas provas de atletismo.

A proporção desigual de acesso ao esporte por homens e mulheres passa por questões culturais e históricas, podendo ser representada por acesso desigual aos bens valorizados e aos recursos de nossa sociedade. Segundo Theberge (2002) essas diferenças parecem indicar uma exclusão relativa da mulher em uma atividade que é culturalmente valorizada, pois o apoio público ao esporte se manifesta de uma série de maneiras, incluindo a locação de programas em instituições educacionais, além de suporte através de incentivos de taxas para donativos e publicidade de eventos e propagandas. $\mathrm{O}$ esporte não representa simplesmente a desigualdade de gênero, mas contribui para sua manutenção nos contextos sociais que o transcendem.

Segundo Boutilier e SanGiovani (1983) existem três razões pelas quais os homens continuam resistindo à entrada das mulheres no esporte. A primeira diz respeito ao desejo de manter o esporte como uma agência de socialização que prepara os homens para os papéis adultos no setor público, particularmente no mercado de trabalho e vida política, já que o esporte apresenta características como trabalho em equipe, liderança, pensamento estratégico, competição, entre outras, que se apresentam como exigências nessa área em que os homens não querem dividir espaço com as mulheres. A segunda seria para a manutenção do ranking hierárquico dos papéis sexuais, especificamente na preferência de papéis masculinos delegando aos homens papéis mais importantes e relevantes devido à sua condição sexual. A terceira razão seria a de preservar um núcleo exclusivamente masculino que permitiria a expressividade e intimidade, qualidades tipicamente ausentes do que geralmente se considera comportamento apropriado para homens. Podemos ter como exemplo dessa terceira razão o comportamento dos homens em um jogo de futebol, no qual as sensações e emoções experenciadas permitem que eles se abracem,

Movimento, Porto Alegre, v.12, n. 01, p. 105-131, janeiro/abril de 2006. 
chorem, gritem, sofram, ou seja, comportamentos que não são adotados e muitas vezes não aprovados em seus cotidianos.

As razões supramencionadas parecem demonstrar algum medo de que as mulheres ocupem os espaços antes apenas ocupados pelos homens. De acordo com dados britânicos analisados por Dunning (1994), canções de jogadores de Rugby ridicularizando as mulheres e tratando-as como objetos sexuais, poderia ser um indício de que as mulheres estariam oferecendo certa ameaça à reserva masculina. Ainda hoje há uma representação muito importante na consciência popular que vê a simples presença das mulheres no esporte como estranha. $\mathrm{O}$ medo da masculinização física das atletas estava associado ao receio de que elas se afastassem da vida heterossexual e assim questionassem a divisão específica do sexo no trabalho, o eixo central de uma sociedade orientada para a tarefa. As reportagens esportivas têm como aspecto fundamental, não o esporte e sim o seu corpo como objeto de prazer para o homem. Essa é uma estratégia útil, quando a mulher começa a ir muito fundo e ameaçar os santuários masculinos, isto é, a sua vaporização e reconstituição simbólica como objeto, ou como um tópico para piadas e referências de preconceitos sexuais (como e estereótipo de "sapatona").

O quadro descrito acima não se restringe somente às mulheres atletas, mas em algumas medidas também a todas que direta ou indiretamente atuam no esporte, como oficiais de arbitragem, apresentadoras de TV, repórteres, entre outras.

No caso específico do futebol, à medida que a atleta se torna mais brilhante, mais ela marca a si como desviante. A mulher atleta vive uma severa contradição, pois vencer como atleta supõe falhar como mulher, pois num certo modo simbólico ela se tornou um homem e, inevitavelmente, é comparada ao homem atleta. Em uma história que os esportes foram concebidos para e pelos homens, as mulheres têm levado desvantagem, pois não são biologicamente mais fortes e velozes que os homens, embora as caracte-

Movimento, Porto Alegre, v.12, n. 01, p. 105-131, janeiro/abril de 2006. 
rísticas nas quais as mulheres se destacam, como a flexibilidade, raramente são postas em destaque. Contudo, o avanço dos estudos acadêmico-científicos, no âmbito das diversas ciências, tem sido o diferencial para mostrar que, consideradas as necessárias adaptações às diferenças fisiológicas e sociais, homens e mulheres podem e precisam estar envolvidos com as atividades físicas e esportivas em qualquer nível de desenvolvimento.

\section{Projeto Gente: meninas, futebol e resiliência.}

Nessa seção apresentaremos os resultados da coleta e da análise dos dados do estudo. Os dados foram coletados com as seguintes técnicas: observação participante do comportamento e conteúdo das falas das alunas durante as aulas e atividades extra futebol, o que foi registrado em diário de campo; entrevistas com uma amostra retirada do grupo de alunas participantes; entrevistas com as mães das alunas selecionadas na amostra.

Para o registro de informações no diário de campo, utilizamonos de questões levantadas que nos orientassem o que observar e o que estar perguntando às mesmas.

Quanto às entrevistas, pensamos que seriam necessárias para dar sustentação aos elementos que possivelmente surgissem na observação participante e, de fato, essas se mostraram de grande valia para as argumentações que foram estabelecidas. A amostra de alunas para as entrevistas foi selecionada a partir dos seguintes critérios: as alunas selecionadas seriam as que possuíssem maior tempo de permanência no Projeto; as que tivessem maior frequiência e as que tivessem maior disponibilidade de tempo, para a realização das entrevistas, já que estas seriam realizadas em horários extras ao futebol. No cruzamento desses critérios, chegamos a um número de cinco meninas, as quais serão chamadas no decorrer do texto de informante 01, 02, 03, 04 e 05. Pensamos que para maior fidedignidade das informações colhidas junto às meninas da amostra, seria interessante colher também informações junto às respec-

Movimento, Porto Alegre, v.12, n. 01, p. 105-131, janeiro/abril de 2006. 
tivas mães (01, 02, 03 e 04. Essa última é também mãe da informante 05), sendo que roteiro utilizado foi o mesmo para os dois grupos. A forma de entrevista escolhida foi do tipo semi-estruturada.

O roteiro das observações foi o mesmo utilizado para as entrevistas e na sua estruturação foram considerados, entre outros, os seguintes itens: Influência da família na prática do futebol, preconceitos sofridos pela escolha da modalidade, perspectiva profissional e pessoal, relação social com o sexo oposto, fontes e meios de acesso às informações, seleção das atividades de lazer, posturas de liderança dentro do grupo, conversas durante as aulas. Esses itens foram vistos como contribuições fundamentais para a análise, em função de sua relação com as características atribuídas às pessoas resilientes e que foram evidenciadas na revisão de literatura. Informamos ainda que esses mesmos itens que dirigiram o roteiro de coleta de dados foram convertidos em categorias de análise para o tratamento dos dados. A análise dos dados foi realizada de forma qualitativa, sendo que se procurou fazer um confronto das informações coletadas na observação participante (os comportamentos) e nas entrevistas, com os referenciais encontrados na revisão de literatura. Especificamente para a análise das entrevistas e falas coletadas durante a observação participante, seguimos as orientações propostas por Sourioux \& Lerat (2002) para a análise de conteúdo, o que nos permitiu agrupar os dados em categoria, cuja discussão é apresentada nos tópicos a seguir:

\section{a) INFLUÊNCIADAFAMÍLIANA PRÁTICADOFUTEBOL:}

Durante as observações realizadas em aulas e através das reuniões com os pais verificamos que as mães têm uma presença maior na vida das alunas, principalmente quando se trata do cotidiano, e são elas que estão presentes nas reuniões do Projeto inclusive, sendo responsáveis positivamente ou negativamente no incentivo à prática do futebol. Em algumas situações existe o incentivo, principalmente quando as mães sentem que as meninas estão felizes em participar das aulas, o que pode ser constatado na

Movimento, Porto Alegre, v.12, n. 01, p. 105-131, janeiro/abril de 2006. 
fala da mãe 02: "Acho que fazer exercício físico é muito bom pra ela". Mas, em outros momentos elas deixam de incentivar por achar que suas filhas possam se machucar quando estão doentes ou menstruadas. É interessante notar que mesmo sob a falta de incentivo às alunas continuam freqüentando as aulas e existem casos em que insistem em jogar mesmo estando doentes, elas se medicam e voltam para o campo. Os casos são muitos, que se referem a essa "perseverança" das meninas, dos quais podemos destacar: Uma de nossas alunas mesmo estando com o braço quebrado, ficando assim impossibilitada de jogar continua frequientando as aulas auxiliando a professora na arbitragem. Em outra ocasião, quando uma de nossas alunas foi impedida pelo pai de freqüentar as aulas do Projeto, por ter tido comportamento inadequado na escola, ela, porém, continuou a frequientar as aulas às escondidas (é claro, sem o conhecimento dos instrutores). Esse fato demonstra que mesmo frente a obstáculos as meninas resistem e continuam jogando, manifestando-se perseverantes, característica essa de pessoas resilientes, conforme as afirmações que encontramos em Ruegg apud Tavares (2001).

A presença de pais em nossas aulas se restringiu a um único momento em que a presença de um pai influenciou o comportamento de sua filha, a qual nesse dia apresentou uma postura bastante agressiva dentro de campo, parecendo querer mostrar a ele, através de características "masculinas" de jogar que ela poderia ser tão boa como os meninos.

Este fato pode ter sido uma forma de chamar a atenção a fim de provar sua competência como jogadora. Nesse caso, a menina pode ter usado do princípio de ceder a uma concepção hegemônica temporariamente, sem perder sua trajetória normal, isto é, manifestar que pode jogar como menino, mas se portar como menina. Dessa forma, ela mostra em última instância, que pode jogar futebol com bom nível técnico, comparado aos meninos, mas permanecer feminina. Se assim o for, a estratégia de resistência tende a ser inteligente, saindo de uma situação complicada e difícil, sem 
perder o equilíbrio. Essa tem se configurado com uma forma de resiliência auto-conquistada, uma vez que sus formação não tem sido objeto da educação formal, conforme denunciam Tavares (2001) e Pereira (2001).

\section{b) PRECONCEITOS SOFRIDOS:}

Nos relatos durantes as aulas que tinham como tema o preconceito no esporte verificamos que mais da metade das alunas já sofreu algum tipo de preconceito por jogarem futebol. Esse preconceito se manifesta através dos termos pejorativos aos quais as meninas são submetidas ou em forma de críticas ao seu modo de jogar. É comum elas ouvirem que não sabem jogar, e frases do tipo: "Futebol não é coisa pra mulher", também são ouvidas constantemente. Demonstram-se aqui preconceitos bem antigos que consideravam a mulher como um ser frágil, que não deveria se envolver com atividades consideradas masculinas, pois poderiam por em risco a sua feminilidade. Esse fato também pode indicar, como vimos em Boutilier e SanGiovani (1983) e Dunning (1994), que as críticas feitas pelos homens teriam um papel de desencorajálas a fim de que elas não ocupassem novas posições que se lhes têm sido apresentadas. Mesmo diante das severas críticas, as alunas resistem e continuam freqüentando as aulas e ao contrário do que se poderia imaginar, elas se orgulham de dizer que jogam futebol, o que nos leva a pensar que estariam desafiando uma área de reserva masculina, mostrando que esse espaço também deve ser conquistado pelas mulheres. As mães entrevistadas disseram não ter preconceito quanto ao fato das filhas praticarem futebol, o que pode ter sido um fator estimulante para elas.

Um caso especial que ocorreu no projeto foi a entrada de uma menina considerada pela turma como "sapatão" (um dos termos pejorativos), e sua presença foi motivo de distanciamento das demais alunas. No início pensamos que fosse discriminação a alguém diferente delas, mas olhando de forma mais cuidadosa, percebemos que poderia estar sendo, dentre outras hipóteses, uma

Movimento, Porto Alegre, v.12, n. 01, p. 105-131, janeiro/abril de 2006. 
maneira de afastar do time alguém que trouxesse para o grupo uma imagem que elas não queriam transmitir, já que a presença dessa garota poderia trazer mais obstáculos de acesso ao espaço que elas estavam conquistando com tantas dificuldades. Essa, apesar de parecer um atitude também discriminatória, não deixa de ser um pensamento estratégico, recurso bastante enfático no referencial teórico defendido por Boutilier e SanGiovani (1983), e corroborado pelos estudos de Perim (2005).

\section{c) PERSPECTIVA PESSOAL E PROFISSIONAL:}

Características como crescimento pessoal e social fazem parte de pessoas resilientes, conforme indicado por Yunes e Szymanski (2001). Verificamos em nossas alunas o interesse em crescer profissionalmente quando as vemos preocupadas com os estudos e com os cursos que possam ajudá-las no futuro. Os cursos mais citados foram os de informática e línguas, por saberem que o mercado de trabalho exige tais qualificações.

Verifica-se que elas não querem mais casar cedo, como suas mães. Primeiro elas pensam em estudar e trabalhar, para depois então terem os (poucos) filhos. Essa informação parece mostrar a convicção das meninas, uma vez que as falas são confirmadas pelas mães entrevistadas. Durante a entrevista, quatro informantes afirmaram que queriam ter apenas dois filhos, pois pretendiam maior disponibilidade de tempo para se dedicarem aos estudos e ao trabalho, sendo que a informante 03 disse não querer ter filhos e nem casar, porque pensa em trabalhar para ajudar a família. Ter famílias pequenas faz parte do comportamento de pessoas resilientes, aspecto que pode ser comprovado pela fala das meninas. Na frase dita por uma aluna em aula: "Não quero aprender a cozinhar, porque senão além de ter que limpar a casa vou ter também que fazer a comida. Quando eu casar meu marido vai dividir as coisas comigo", pode-se inferir uma revolta quanto a papéis pré-determinados pela sociedade e a necessidade de ter uma vida diferente daquela que as gerações anteriores tiveram. Se

Movimento, Porto Alegre, v.12, n. 01, p. 105-131, janeiro/abril de 2006. 
retomarmos Antunes (2003), podemos dizer que há evidências de anseios por independência pessoal, social e profissional, confirmando-se novamente características de resiliência.

\section{d) COMPORTAMENTOS DENTRO DE CAMPO:}

Observamos que o comportamento das alunas em relação ao jogo foi mudando ao longo de período. Um exemplo disso é a forma como elas lidavam quando uma jogadora se machucava durante o jogo; antes elas paravam e ajudavam a jogadora, porém, hoje o jogo continua e a aluna que machucou logo se levanta e continua a jogar, o que parece indicar que estão deixando o "sentimentalismo" de lado e passando a ser mais "racionais". No pensamento de Souza Neto (2005), isso seria uma "conquista", mas não um processo de transformação geral. Temos que concordar com a consideração do autor, pois se observarmos os "palavrões" proclamados pelas meninas, veremos que antes não existiam e atualmente são muito freqüentes, mas, embora esse comportamento venha se assemelhando ao dos meninos elas ainda apresentam uma característica considerada tradicionalmente na cultura local como sendo própria do gênero feminino: o choro. É muito comum diante de situações difíceis que elas chorem e não tenham vergonha de demonstrar, podendo indicar que embora em alguns comportamentos elas se assemelhem aos meninos em outros elas ainda querem ser "femininas" não perdendo suas características de serem mulheres.

\section{e) COMPORTAMENTOS DE LIDERANÇA:}

Quatro das cinco alunas entrevistadas disseram ter uma postura de liderança em pelo menos um dos grupos que mantém relações, seja na escola, no comando da turma, em casa perante os irmãos ou junto às amizades. Durante as aulas o comportamento de liderança aparece em iniciativas de distribuição de coletes, divisão dos times, reivindicações aos professores, sugestões de temas de aula, iniciar o aquecimento, organizar o time, delegar posições, entre outros. Na escola as informantes alegaram ter um

Movimento, Porto Alegre, v.12, n. 01, p. 105-131, janeiro/abril de 2006. 
comportamento de liderança quando organizam eventos, jogos escolares e estão à frente das reivindicações para mudanças de datas de provas. Em casa esse comportamento se manifesta na apropriação de tarefas que deveriam se realizadas pelos pais como exigir que os irmãos estudem, distribuição de tarefas, controle de gastos, sendo líderes até mesmo perante aos irmãos mais velhos. Durante a entrevista com a mãe 02 foi confirmada a liderança da filha em casa, principalmente devido ao fato dos pais trabalharem em período integral. Algumas alunas que demonstravam um comportamento passivo dentro de campo, não o mantinham fora dele, e o contrário também aconteceu parecendo indicar que o grupo alterna lideranças. A alternância pode gerar "interações", fazendo com que a liderança necessária para o comportamento resiliente, segundo Pereira (2001), vá se completando.

\section{f) COMPORTAMENTOS NA FAMÍLIA:}

A família das alunas geralmente se caracteriza pela presença de pais severos que proíbem suas filhas de namorar e sair para festas, e que pregam tarefas diferenciadas em função do sexo. $\mathrm{O}$ resultado dessa repressão é a rebeldia e a falta de confiança que elas depositam neles recorrendo sempre que possível às mães, que aparecem constantemente como um ponto de apoio para as situações difíceis. A informante 02 manifesta seu descontentamento através de um comportamento rebelde, o que resulta em brigas com os pais. Sua mãe disse em entrevista que o marido não achava que seu filho devia fazer as mesmas atividades que suas filhas, principalmente quando o assunto era serviço doméstico. Ela relatou uma fala do marido assim: “ $O$... (nome do filho) coitado! As meninas brigam com ele porque ele não ajuda elas, mas é porque é homem, não sabe fazer essas coisas! ". Confirmase assim, a diferença de atividades atribuídas aos sexos, restando às mulheres os serviços domésticos. É interessante observar que quando perguntamos à mãe se ela achava que existiam atividades exclusivas para os sexos, a resposta foi negativa e que na casa dela não havia esse tipo de preconceito. Essa é uma contradição 
que talvez possa explicar o motivo das brigas relatadas pela informante 02 . A informante 01 disse que o motivo das brigas em casa deve-se ao fato do pai ser extremamente conservador proibindo-a de namorar, fato esse comprovado pela sua mãe, que ao contrário do pai aprova o namoro. As outras informantes apesar de não concordarem com algumas situações que acontecem em casa acabam aceitando, para evitar conflitos que podem se agravar, aparecendo aqui a característica de resiliência similar ao item "a" dessa seção, a capacidade de ceder temporariamente diante de uma disputa, aguardando um momento mais oportuno para uma ação diferente. Porém, esse comportamento de aceitação não significa que elas deixem de lutar pelos seus objetivos, pois uma fala comum nas entrevistas é a de que, quando forem independentes financeiramente, não serão coniventes com esse tipo de comportamento.

Está presente em todas as meninas do Projeto a tarefa de ajudar nos serviços domésticos, sendo que algumas delas são responsáveis por todo ele, pois as mães trabalham em período integral. A mãe das informantes 04 e 05 confirmou a realização de tarefas domésticas pelas filhas. Observamos que os irmãos não possuem as mesmas obrigações, pois para a família, serviço doméstico deve ser restrito às mulheres. Além das obrigações domésticas, os pais fazem questão que as alunas dediquem uma parte do tempo aos estudos, o que pode ser comprovado com a preocupação que duas mães apresentaram com a vida escolar de suas filhas parecendo mostrar uma preocupação com seus futuros profissionais, já que a maioria dos pais não teve a oportunidade de concluir os estudos ou até mesmo de iniciá-los. Vemos nas alunas o desejo de serem realizadas financeiramente para ajudar a família, o que pode ser evidenciado no grande número de meninas que trabalham. A despeito dos debates atuais sobre o trabalho juvenil, seguindo Perim (2005) cremos que esse comportamento auxilia na formação da identidade das meninas. $\mathrm{O}$ dinheiro recebido é destinado na maioria das vezes para ajudar nas despesas em casa e para que possam também comprar aquilo que desejam economi-

Movimento, Porto Alegre, v.12, n. 01, p. 105-131, janeiro/abril de 2006. 
zando o dinheiro da família. Em entrevista a mãe 02 disse que a filha irá começar a trabalhar para poder arcar com seus gastos: "Ela nunca trabalhou, só falava pra ela estudar, mas agora eu deixo pra ela poder comprar as coisinhas dela".

\section{g) HISTÓRIA DE VIDA/TRANSTORNOS FAMILIARES:}

Pessoas resilientes apresentam uma história de vida sofrida e, em quatro informantes, percebemos que esse aspecto se configurou em nas seguintes situações: a perda do pai, doença de entes queridos, pais alcoólatras que viviam em conflitos familiares, dificuldades financeiras, entre outras. A informante 05 disse em entrevista: "Teve uma vez que meu pai pegou um facão e ameaçou a minha mãe. A gente teve que mudar para ele não achar a gen$t e$ ". Durante entrevista com a mãe 04 (lembremos que é também mãe da informante 05), percebemos que o transtorno familiar citado anteriormente foi tão grande que ela teve dificuldade em falar desse assunto. "É melhor não falar nisso mais, coisa triste a gente esquece". A informante 03 relatou que o pai veio a falecer quando tinha dois anos de idade, sendo que após esse acontecimento a mãe passou a dedicar-se exclusivamente ao trabalho e a avó, que tinha a responsabilidade de cuidar da casa e dos irmãos, perdeu a visão, restando a ela a responsabilidade pela casa, pelo irmão e pela avó. Apesar das histórias difíceis percebemos uma grande admiração das meninas pelos pais, parecendo demonstrar que elas compreendem a difícil tarefa de educar os filhos sob dificuldades financeiras. Se considerarmos os trabalhos de Glantz \& Johnson, e Constantine et al. apud Pereira (2001), podemos dizer que isso alimenta sua perseverança, logo, também a resiliência.

\section{h) RELAÇÃO COM O SEXO OPOSTO:}

As meninas se mostraram interativas com os meninos durante as atividades extracurriculares, desde que nenhum deles fosse ao campo assisti-las treinar. Elas alegam que eles vão assisti-las a fim de posteriormente ridicularizá-las para os outros meninos, o que é um comportamento esperado, como vimos em Dunning (1994).

Movimento, Porto Alegre, v.12, n. 01, p. 105-131, janeiro/abril de 2006. 
Todas as alunas entrevistadas já namoraram e quatro delas afirmaram não trocar o futebol pelo namorado. É interessante ressaltar que as meninas, de um modo geral quando chegam à adolescência diminuem ou deixam de praticar atividades físicas, muitas vezes esse tempo é dedicado nessa fase aos namoros, porém, o mesmo não acontece com nossas alunas, pois mesmo tendo atitudes comuns à adolescência, não deixam de freqüentar as aulas. Mesmo as alunas que têm namorado, continuam freqüentando as aulas, inclusive quando necessário, levando o namorado para assisti-las. Uma das características que um menino deve ter para que elas iniciem um namoro é aceitar suas decisões de jogar futebol, podendo demonstrar que fazem questão de tomar as decisões de suas vidas sem interferências do sexo oposto (Perim, 2005). Admiram meninos que sejam sinceros, saibam conversar e dividam tarefas com as meninas. É unânime o discurso de que quando se casarem, a função de cuidar dos filhos e da casa será de responsabilidade de ambos, demonstrando aqui mais uma vez um discurso igualitário sobre papéis sexuais.

É bastante freqüente durante as aulas conversas sobre os garotos e durante o trajeto de volta pra casa elas assobiam para os alunos da universidade, mostrando que são meninas como as outras, que não se tornaram masculinizadas pelo fato de jogar futebol. Este aspecto pode também indicar uma atitude de defesa das garotas para não terem suas imagens aliadas ao comportamento homossexual, já que essa opção sexual é vista com olhares preconceituosos, e cuja explicação já vimos em Dunning (1994).

\section{i) ATIVIDADES DE LAZER:}

As atividades de lazer das meninas são os esportes praticados no final de semana (extra futebol), passeios em casas de parentes, festas de amigos, televisão e músicas. O tempo dedicado ao lazer é pequeno devido às obrigações domésticas que as meninas cumprem como arrumar a casa, cozinhar, cuidar e levar os irmãos à escola, entre outros, sendo que algumas meninas ainda

Movimento, Porto Alegre, v.12, n. 01, p. 105-131, janeiro/abril de 2006. 
trabalham para ajudar no orçamento familiar. De acordo com a mãe 04, o tempo dedicado ao lazer só é permitido depois que as filhas terminam os deveres escolares e as tarefas de casa.

O horário das aulas no Projeto sofreu modificações em função do trabalho de algumas meninas. Depois de tantas obrigações elas ainda encontram tempo e disposição para ir às aulas, mostrando que apesar de existirem muitos obstáculos impedindo-as de jogar futebol, elas insistem e continuam a jogar, confirmando os aspectos de perseverança apontados no item "g" desta seção.

\section{j) ACESSO À INFORMAÇÃO:}

Todas as alunas alegaram durante as aulas que a televisão é o meio mais comum de informação, característica essa bem comum entre as pessoas de classe popular. A programação abrange em sua maioria novelas e programas esportivos. Nota-se aqui que os programas esportivos não são privilégios do gênero masculino, pois, as meninas, apesar de reclamarem da pouca divulgação do futebol feminino, assistem com freqüência aos noticiários esportivos. O acesso a livros, revistas e jornais é raro e se restringe às tarefas escolares, mas apesar disso percebemos que elas não se posicionam acriticamente sobre estes, não se mostrando ingênuas diante de propagandas enganosas. Esse fato foi comprovado quando as questionamos durante as aulas sobre a pequena divulgação do esporte feminino, e sobre a relação do esporte com a estética corporal das atletas. As meninas se posicionaram criticamente dizendo não concordar com essas atitudes denominadas por elas como atitudes preconceituosas. Lembremos que a atitude crítica foi também apontada por Tavares (2001) como característica do comportamento resiliente.

\section{Concluindo...}

Essa investigação teve início quando desconfiamos que as meninas freqüentadoras do futebol no Projeto Gente, na UFV, aderiam às atividades e permaneciam somente pelo mesmo motivo 
alegado pelos meninos (Borges et alii, 2004), ou seja, somente pelo gosto. Sentimos que no caso das meninas esse motivo ainda precisava ser observado melhor. Analisando a história de luta diária da mulher na sociedade e no esporte, percebemos que o motivo gosto poderia ser insuficiente para a adesão ao projeto, já que nossas alunas têm enfrentado ao longo de suas vidas preconceitos comuns às mulheres que tentam ingressar em áreas de reserva masculina. A história nos mostra a árdua trajetória da mulher na conquista por novas oportunidades na carreira profissional, na vida conjugal, nas escolhas de estilos de vida e também no esporte. Essa trajetória tem sido percorrida com muita luta e persistência, porém, existem grandes obstáculos que poderiam fazê-las desistir.

Diante de nossas alunas, pensamos nas barreiras diárias que elas enfrentam tais como: Tarefas domésticas restritas à figura feminina, preconceitos relacionados ao fato de estarem praticando um esporte considerado "masculino", falta de apoio da sociedade para praticarem o esporte, estigmatização feminina, entre outras, que seriam suficientes para o abandono da prática, porém, o que vem ocorrendo é justamente o contrário. Nossas meninas têm resistido e consequientemente dando continuidade ao projeto. Pensamos que apenas o motivo gosto seria insuficiente para que nossas meninas ingressassem e permanecessem nas aulas. Assim, recorrendo a estudos de Sociologia e psicologia, passamos a procurar respostas na possível existência de comportamentos resilientes.

Na tentativa de confirmação da existência ou não dos supostos comportamentos resilientes, traçou-se um itinerário metodológico com utilização de observação participante e entrevistas que possibilitassem a emersão de dados favorecedores da investigação. Diante dos dados coletados percebemos que alguns elementos encontrados apontaram para a existência de comportamentos resilientes, já que nossas meninas apresentaram algumas características desse comportamento, tais como: capacidade de superar obstáculos diante do preconceito sofrido pela sociedade, a falta de incentivo à prática e a imposição para a realização de

Movimento, Porto Alegre, v.12, n. 01, p. 105-131, janeiro/abril de 2006. 
tarefas domésticas que ocupam grande parte do seu tempo. Outros traços resilientes também foram verificados em algumas alunas como: melhor desenvolvimento intelectual, maior nível de autoestima; maior grau de autocontrole; desejo de ter famílias menos numerosas; história de vida sofrida; intencionalidade de melhor preparação para o mundo do trabalho, preocupação com a evolução tática sem a perda da feminilidade, a busca pelo gênero oposto, entre outros; permitindo dizer que através do futebol elas parecem estar conseguindo mostrar que também podem realizar papéis "masculinos" com sucesso sendo elas mesmas, transferindo esse ideal para outras áreas além do esporte, seja na vida social ou na vida profissional.

Porém, nas falas captadas pelos instrumentos de coleta, observamos que o comportamento resiliente parece se manifestar no grupo de meninas, isto é, todas têm características de resiliência, mas, individualmente esse comportamento não se mostra homogêneo. Ao que tudo indica, apesar de algumas meninas, individualmente, não declararem possuir traços atribuídos pela literatura à resiliência, observamos que os comportamentos e falas apresentadas durante as aulas parecem manifestar um comportamento resiliente inconsciente. Pensamos, então, que o convívio das meninas que mais parecem resilientes com aquelas que cujo esse comportamento não é tão marcante, possa fazer com que surja a resiliência enquanto uma manifestação coletiva, e que dessa maneira o grupo consiga se manter apesar das dificuldades individuais e coletivas para a permanência.

Outros indicadores encontrados na investigação parecem corroborar com a existência de comportamentos resilientes nas meninas, os quais juntamente com os comentados aqui, indicam que as mesmas não estariam freqüentando as aulas apenas pelo gosto da modalidade. Contudo, apenas nos foi possível socializar aqueles que consideramos essenciais ao alcance dos objetivos do estudo e, em última instância possam sugerir aos organizadores e professores do Projeto que, sabendo agora desse comportamento resiliente 
das alunas, possam valorizar ainda mais a participação das meninas no Projeto, incentivando-as a percorrer suas árduas trajetórias e reconhecendo, em seus esforços, a luta da mulher na conquista de sua liberdade e igualdade de direitos.

Resilience: A possibility for bringing and keeping girls into womens soccer

Abstract: This study investigates the possible presence of resilient behaviors in girls who practice soccer, taking as focus group girls from a lower class, who practice the sport in Viçosa-MG. Because of the difficulties faced towards bringing and keeping girls in soccer, which are common due to social position and the genre of the focus group, it is believed that resilience keeps them practicing, as a resource towards the wide movement for the feminine social emancipation. The methodology was based on participant observation, alongside with notes, photographs and filming that could prove the girl's possible resilient behavior.

Key words: Resilience. Genre. Soccer.

Resilicencia: Una posibilidad de adhesion y permanencia en la practica del futbol feminino Resumen: El presente estudio investiga la posible existencia del comportamiento resilicente en las chicas practicantes del fútbol, teniendo como muestra un grupo de niñas, de clase pobre, practicantes de la modalidad en Viçosa-MG. Frente a las dificultades encontradas para la adhesión y permanencia nel fútbol, comunes a la clase social y al genero del grupo elegido, é posible creer que la resilicencia las mantiene en la practica, como un recurso para la conquista de áreas de actuación masculina. La metodología utilizada fue compuesta de observación participante, apuntes, fotografías e filmación que hicieran posible evidenciar el posible comportamiento resilicente de las niñas.

Palabras-clave: Resilicencia. Género. Fútbol.

Movimento, Porto Alegre, v.12, n. 01, p. 105-131, janeiro/abril de 2006. 


\section{REFERÊNCIAS}

ALMEIDA, R. S. A imagem do atleta de futebol feminino na mídia impressa brasileira: Análises e reflexões. In: CONBRACE, 12. Anais. Campinas/SP: CBCE, 2003.

ALVAREZ, A. M. S. A Resiliência e a história de vida de jovens moradores de rua: a família, os amigos, o sentido da vida. Disponível em: www.bireme.br/bvs/adolec (S.D.)

ANTUNES, C. Resiliência: A construção de uma nova pedagogia para uma escola pública de qualidade. Petrópolis/RJ: Vozes, 2003.

-BORGES, C. N. F. et alii. O gosto como perspectiva de motivação, manutenção e propulsão da prática esportiva. Coletânea do $3^{\circ}$ Congresso Científico Latino Americano de Educação Física e Esportes. Piracicaba/SP: Editora da UNIMEP, 2004

BOUTILIER, MA. SANGIOVANI, L. The sporting woman. CHAMPAIGN; ILLINOIS: HUMAN KINETICS, 1983

COSTA, D. M. \& GUTHRIE, S. R. Mulheres e esporte - perspectivas interdisciplinares Champaign: Editores Human Kinetics, 1994.

DUNNING, E. Sport as a male preserve: notes on the social sources of masculine identity and its transformations. pp. 163-178, In BIRREL, S \& COLE, C. Women, Sport, and Culture. Editors. Champain: Human Kinetics, 1994.

PEREIRA, A. M. S. Resiliência, personalidade, stress e estratégias de coping. In TAVARES, J. (Org.) Resiliência e educação. São Paulo: Cortez, 2001.

PERIM, M. F. Reflexões Sobre Lúdico, Trabalho, Gênero e Classe na Formação da Identidade de Jovens-Meninas do MNMMR. In Anais do XIV CONBRACE. Porto Alegre/RS: UFRS, 2005.

PFISTER, G Cultura Corporal, Mitos e Feminilidade e o discurso de Gênero na Alemanha (1919-1933). La comune eredità dello Sport in Europa - Atti del 1 Seminario Europeo di Storia dello Sport , a cura di Arnd Krüger e Angela Teja. Coni, Roma, 1997

SILVA, S. R. et alii. Projeto escolinha de futebol do Laranjal. Viçosa/MG: DES/ UFV, 2001

\& PEREIRA, R. S. Projeto Gente - O esporte como um instrumento de prática de liberdade. Viçosa/MG: DES/UFV, 2004 (mímeo)

SOURIOUX, J. L. \& LERAT, P. Análise de Texto: Método Geral e Aplicações no Direito. São Paulo: Martins Fontes, 2002.

Movimento, Porto Alegre, v.12, n. 01, p. 105-131, janeiro/abril de 2006. 
SOUZA NETO, J.C. et alii. A trajetória das conquistas de crianças e adolesecentes In Anais do XII Congresso Brasileiro de Sociologia. Belo Horizonte: UFMG, 2005. TAVARES, J. (Org.) Resiliência e educação. São Paulo: Cortez, 2001.

THEBERGE, N. Toward a Feminist Alternative to Sport as a Male Preserve. In VOTRE, S. Estudos sobre a mulher. Rio de Janeiro, UGF, 2002.

YUNES. M. A. M. \& SZYMANSKI, H. Resiliência: Noção, conceitos afins e considerações críticas. In TAVARES, J. (Org.) Resiliência e educação. São Paulo: Cortez, 2001.

Recebido em: 30/11/2005 Aprovado em: 02/04/2006

Carlos Nazareno Ferreira Borges Rua Hélio Stanciola, 39/101 - Bairro Fátima

36570-000 - Viçosa - MG

carlosnazareno@ufv.br

Movimento, Porto Alegre, v.12, n. 01, p. 105-131, janeiro/abril de 2006. 